\title{
Soft Intervals and Soft Ordered Topology
}

\author{
Gözde Yaylalı1 ${ }^{1}$, Nazan Çakmak Polat ${ }^{2}$, Bekir Tanay ${ }^{3^{*}}$ \\ 1,2,3 Muğla Sıtk1 Koçman Üniversitesi, Fen Fakültesi, Matematik Bölümü, \\ Muğla, +90 2522111488 \\ *btanay@mu.edu.tr \\ *Corresponding author
}

Recieved: $18^{\text {th }}$ November 2016

Accepted: $7^{\text {th }}$ December 2016

DOI: http://dx.doi.org/10.18466/cbujos.302645

\begin{abstract}
In this paper, the concept of soft interval is given and an example for soft Scott topology is illustrated by using the soft intervals. A tabular form for all soft closed intervals is presented. Then soft order topology is introduced and some application of it are expressed. Also we show that, the Soft Scott Topology and Soft Order Topology do not have to be same even on the same soft set.
\end{abstract}

Keywords - Soft Interval, Soft Ordered Set, Soft Ordered Topology, Soft Set, Soft Topology

\section{Introduction}

Molodtsov [19] introduced soft set theory in 1999. Soft set theory is a new approach for modeling the problems in physics, economics, engineering, computer science, medical science and social science by dealing with uncertainties. Maji et. al improve the soft set theory [17] by defining many operators for the soft sets and they also defined fuzzy soft sets [16] and established some results on them. Çağman et.al. [7] gave a matrix representation of soft sets and using this representations made soft set have a rich computer application potential. Recently, the properties and applications on the soft set theory [1], [12], [13], [14], [15], [23], [21] and the fuzzy soft set theory [16], [4], [26], [9], [25], [5] have been studied increasingly. Babitha and Sunil [2] defined soft set relation and [3] ordering on soft sets. Moreover, Park et. al [22] studied the equivalence relations, partitions and functions. The notions of antireflexive kernel, symmetric kernel, reflexive clousure and symmetric clousure of a soft set relation were introduced by Yang and Guo [30] and they proposed soft set relation mappings and inverse soft set relation mappings. The definition of infimum and supremum of the soft set, directed and directed complete soft set were given by Tanay and Yaylalı [28].

While soft topology was introduced by Çağman et. al [6] and structure of soft topology was improved by Roy and Samanta [23], Shabir and Naz [27] defined soft topology in a different approach. Min [18] studied soft regular spaces; Husain and Ahmad [11] studied some new structures such as soft interior and soft boundary. Nazmul and Samanta [20] introduced soft neighborhood. Furthermore, some properties of soft Hausdorff spaces was studied by Varol and Aygün [29] and some new concepts in soft topological spaces was introduced by them. In addition to these, some concepts about soft topological spaces such as, soft interior point, soft continuity were introduced by Zorlutuna [32]. Soft Scott topology which is obtained by directed partially ordered soft set was introduce by Tanay and Yaylalı [28]. Using some definitions and results given in [28], Sayed [24] 
established some characterization results for continuity of partially ordered soft sets by the embbed soft bases technique and soft sobrification via soft Scott topology.

In order to refresh the fundamental concepts of set theory using in this paper, we refer to [8], [10]. In this study we prove some theorems about soft bases. At same time, the concept of soft interval and a tabular form for all soft closed intervals are given. An example for soft Scott topology is illustrated by using the soft intervals. Then soft order topology is introduced and some applications of the Soft Order Topology are expressed. Also we show that on the same soft set, the Soft Scott Topology and Soft Order Topology do not have to be same.

\section{Preliminaries and basic definitions}

Definition 2.1 [19] Let $E$ be the set of parameters, $U$ be an initial universe. Consider $\mathrm{P}(\mathrm{U})$ as a set of all subsets of $U$ and $A$ as a subset of $E$. A pair $(F, A)$ is called a soft set over $U$ where $F: A \rightarrow P(U)$ is a setvalued function. In an other words, the soft set is a parametrized family of subsets of the set U. For every e $\in U, F(e)$ may be considered as a eapproximate elements of the soft set $(\mathrm{F}, \mathrm{A})$.

Definition 2.2 [17] A soft set (F,A) over $\mathrm{U}$ is said to be a Null soft set denoted by $\Phi$, if for every $\varepsilon \in A$, $\mathrm{F}(\varepsilon)=\varnothing$.

Definition 2.3 [17] For two soft sets (F,A) and $(G, B)$ over a common universe $U$ we say that $(F, A)$ is a soft subset of $(G, B)$ if

i) $\quad \mathrm{A} \subseteq \mathrm{B}$, and

ii) $\forall \mathrm{e} \in \mathrm{A}, \mathrm{F}(\mathrm{e}) \subseteq \mathrm{G}(\mathrm{e})$.

We write $(F, A) \widetilde{\subseteq}(G, B)$.

Definition 2.4 [17] Union of two soft sets of (F,A) and $(G, B)$ over the common universe $U$ is the soft set $(H, C)$, where $C=A \cup B$, and for each $e \in C$,

$$
(H, C)= \begin{cases}\mathrm{F}(\mathrm{e}) & , \text { if } e \in \mathrm{A}-\mathrm{B} \\ \mathrm{H}(\mathrm{e})=\mathrm{G}(\mathrm{e}) & , \text { if } e \in \mathrm{B}-\mathrm{A} \\ \mathrm{F}(\mathrm{e}) \cup \mathrm{G}(\mathrm{e}) & , \text { if } \mathrm{e} \in \mathrm{A} \cap \mathrm{B}\end{cases}
$$

We write $(\mathrm{F}, \mathrm{A}) \widetilde{\mathrm{U}}(\mathrm{G}, \mathrm{B})=(\mathrm{H}, \mathrm{C})$.

Definition 2.5 [17] Intersection of two soft sets $(\mathrm{F}, \mathrm{A})$ and $(\mathrm{G}, \mathrm{B})$ over a common universe $\mathrm{U}$ is the soft set $(H, C)$, where $C=A \cap B$, and for each $e \in C$, $\mathrm{H}(\mathrm{e})=\mathrm{F}(\mathrm{e}) \cap \mathrm{G}(\mathrm{e})$. We write $(\mathrm{F}, \mathrm{A}) \widetilde{\cap}(\mathrm{G}, \mathrm{B})=(\mathrm{H}, \mathrm{C})$.

Definition 2.6 [6] The soft complement of a soft set $(F, A)$ is a soft set $(F, A)^{C}=(G, A)$ where $G(x)=$ $\mathrm{U}-\mathrm{F}(\mathrm{x})$ for all $\mathrm{x} \in \mathrm{A}$.

Definition 2.7 [2] Let $(\mathrm{F}, \mathrm{A})$ and $(\mathrm{G}, \mathrm{B})$ be two soft sets over $\mathrm{U}$, then $(\mathrm{F}, \mathrm{A}) \times(\mathrm{G}, \mathrm{B})=(\mathrm{H}, \mathrm{A} \times \mathrm{B})$ is the cartesian product of $(\mathrm{F}, \mathrm{A})$ and $(\mathrm{G}, \mathrm{B})$, where $(\mathrm{a}, \mathrm{b}) \in \mathrm{A} \times \mathrm{B}, \quad \mathrm{H}: \mathrm{A} \times \mathrm{B} \rightarrow \mathrm{P}(\mathrm{U} \times \mathrm{U}) \quad$ and $\mathrm{H}(\mathrm{a}, \mathrm{b})=$ $\mathrm{F}(\mathrm{a}) \times \mathrm{G}(\mathrm{b})$. i.e. $\mathrm{H}(\mathrm{a}, \mathrm{b})=\left\{\left(h_{i}, h_{j}\right) \mid h_{i} \in \mathrm{F}(\mathrm{a}), h_{j} \in \mathrm{G}(\mathrm{b})\right\}$

Definition 2.8 [2] Let $(F, A)$ and $(G, B)$ be two soft sets over $\mathrm{U}$, then a soft set relation $\mathrm{R}$ from $(\mathrm{F}, \mathrm{A})$ to $(G, B)$ is a soft subset of $(F, A) \times(G, B)$. In other words, a soft set relation $R$ from $(F, A)$ to $(G, B)$ is of the form $\mathrm{R}=\left(H_{1}, \mathrm{~S}\right)$ where $\mathrm{S} \subset \mathrm{A} \times \mathrm{B}$ and $H_{1}(\mathrm{a}, \mathrm{b})=$ $\mathrm{H}(\mathrm{a}, \mathrm{b})$ for all $(\mathrm{a}, \mathrm{b}) \in \mathrm{S}$ where $(\mathrm{H}, \mathrm{A} \times \mathrm{B})=$ $(\mathrm{F}, \mathrm{A}) \times(\mathrm{G}, \mathrm{B})$.

Definition 2.9 [2] Let $R$ be a soft set relation on $(\mathrm{F}, \mathrm{A})$, then

1. $R$ is called reflexive if $H_{1}(a, a) \in R, \forall a \in A$.

2. $R$ is called symmetric if $H_{1}(a, b) \in R \Rightarrow$ $\mathrm{H}_{1}(\mathrm{~b}, \mathrm{a}) \in \mathrm{R}$.

3. $R$ is called transitive if $H_{1}(a, b) \in R, H_{1}(b, c) \in R \Rightarrow$ $\mathrm{H}_{1}(\mathrm{a}, \mathrm{c}) \in \mathrm{R}$ for every $\mathrm{a}, \mathrm{b}, \mathrm{c} \in \mathrm{A}$.

Definition 2.10 [3] A binary soft set relation $R$ on $(\mathrm{F}, \mathrm{A})$ is called an antisymmetric relation if $\mathrm{F}(\mathrm{a}) \times \mathrm{F}(\mathrm{b}) \in \mathrm{R}$ and $\mathrm{F}(\mathrm{b}) \times \mathrm{F}(\mathrm{a}) \in \mathrm{R}$ for every $\mathrm{F}(\mathrm{a})$, $\mathrm{F}(\mathrm{b}) \in(\mathrm{F}, \mathrm{A})$ imply $\mathrm{F}(\mathrm{a})=\mathrm{F}(\mathrm{b})$.

Definition 2.11 [3] A binary soft set relation $\leq$ on $(\mathrm{F}, \mathrm{A})$ which is reflexive, antisymmetric and transitive is called a partial ordering on a soft set $(\mathrm{F}, \mathrm{A})$. The triple $(\mathrm{F}, \mathrm{A}, \leq)$ is called a partially ordered soft set.

Definition 2.12 [28] Let (F,A) be a soft set equipped 
with reflexsive, transitive soft set relation $\leq$. This relation is called preorder relation and $(\mathrm{F}, \mathrm{A})$ is a preordered soft set.

Definition 2.13 [3] Let $\leq$ be an ordering of $(\mathrm{F}, \mathrm{A})$ and $\mathrm{F}(\mathrm{a})$ and $\mathrm{F}(\mathrm{b})$ be any two elements in $(\mathrm{F}, \mathrm{A})$. If $F(a) \leq F(b)$ or $F(b) \leq F(a)$, then $F(b)$ and $F(a)$ are comparable in the ordering. If they are not comparable, then $\mathrm{F}(\mathrm{a})$ and $\mathrm{F}(\mathrm{b})$ are incomparable.

Definition 2.14 [3] If $(G, B, \leq)$ is a partially ordered soft set then,

a) For $b \in B$, if $G(b) \leq G(x)$ for all $x \in B$, then $G(b)$ is the least element of $(\mathrm{G}, \mathrm{B})$ in the ordering ' $\leq$ '.

b) For $b \in B$, if there exists no $x \in B$ such that $G(x) \leq G(b)$ and $G(x) \neq G(b)$, then $G(b)$ is a minimal element of $(\mathrm{G}, \mathrm{B})$ in the ordering ' $\leq$ '.

$\left.a^{\prime}\right)$ For $b \in B$, if for every $x \in B G(x) \leq G(b)$, then $G(b)$ is the greatest element of $(G, B)$ in the ordering ' $\leq$ '.

$\left.b^{\prime}\right)$ For $b \in B$, if there exists no $x \in B$ such that $G(b) \leq G(x)$ and $G(x) \neq G(b)$, then $G(b)$ is a maximal element of $(\mathrm{G}, \mathrm{B})$ in the ordering ' $\leq$ '.

Definition 2.15 [28] Let $\leq$ be an ordering of $(\mathrm{F}, \mathrm{A})$, let $(\mathrm{G}, \mathrm{B}) \widetilde{\simeq}(\mathrm{F}, \mathrm{A})$.

a) For $\mathrm{a} \in \mathrm{A}, \mathrm{F}(\mathrm{a})$ is a lower bound of $(\mathrm{G}, \mathrm{B})$ in the partially ordered soft set $(F, A, \leq)$ if $F(a) \leq G(x)$ for all $\mathrm{x} \in \mathrm{B}$.

b) For $a \in A, F(a)$ is called infimum of $(G, B)$ in $(\mathrm{F}, \mathrm{A}, \leq)$ (or the greatest lower bound) if it is the greatest element of the set of all lower bounds of the soft subset $(G, B)$ in $(F, A, \leq)$.

Similarly,

$\left.a^{\prime}\right)$ For $\mathrm{a} \in \mathrm{A}, \mathrm{F}(\mathrm{a})$ is an upper bound of $(\mathrm{G}, \mathrm{B})$ in the partially ordered soft set $(F, A, \leq)$ if $G(x) \leq F(a)$ for all $\mathrm{x} \in \mathrm{B}$.

$\left.b^{\prime}\right)$ For $a \in A, F(a)$ is called supremum of $(G, B)$ in $(\mathrm{F}, \mathrm{A}, \leq)$ (or the least upper bound) if it is the least element of the set of all upper bounds of the soft subset $(\mathrm{G}, \mathrm{B})$ in $(\mathrm{F}, \mathrm{A}, \leq)$.
Definition 2.16 [28] Let $(\mathrm{F}, \mathrm{A})$ be a soft set. If it is a soft set with a finite parameter set, the soft set $(\mathrm{F}, \mathrm{A})$ is called a finite soft set.

Definition 2.17 [28] Let $(\mathrm{F}, \mathrm{A})$ be a preordered soft set. A soft subset $(G, B)$ of $(F, A)$ is called directed if it is nonnull and every finite soft subset of $(G, B)$ has an upperbound in $(G, B)$.

Definition 2.18 [28] Let $(\mathrm{F}, \mathrm{A})$ be a soft set with a preorder $\leq$. For $(\mathrm{G}, \mathrm{B}) \widetilde{\widetilde{\subseteq}}(\mathrm{F}, \mathrm{A})$, the soft subset $(\mathrm{K}, \mathrm{D})$ of $(F, A)$ where $D=\{a \in A: G(b) \leq F(a)$ for some $b \in B\}$ and $\mathrm{K}=\left.F\right|_{D}$ is denoted as $\uparrow(\mathrm{G}, \mathrm{B})=(\mathrm{K}, \mathrm{D}) .(\mathrm{G}, \mathrm{B})$ is called an upper soft set iff $(G, B)=\uparrow(G, B)$.

Definition 2.19 [28] A partially ordered soft set is called a directed complete soft set if all directed soft subset has a supremum.

\section{Soft Topology}

Definition 3.1 [23] A soft topology $\tilde{\tau}$ on a soft set $(\mathrm{F}, \mathrm{A})$ is a family of soft subsets of $(\mathrm{F}, \mathrm{A})$ if it satisfies the following properties

i) $\Phi,(\mathrm{F}, \mathrm{A}) \in \tilde{\tau}$;

i) If $(G, B),(H, C) \in \tilde{\tau}$, then $(G, B) \widetilde{\cap}(H, C) \in \tilde{\tau}$;

iii) If $\left(\mathrm{F}_{\alpha}, \mathrm{A}_{\alpha}\right) \in \tilde{\tau}$ for all $\alpha \in \Lambda$, an index set, then $\left(F_{\alpha}, A_{\alpha}\right)_{\alpha} \in \tilde{\tau}$. If $\tilde{\tau}$ is a soft topology on a soft set $(\mathrm{F}, \mathrm{A})$, then $(\mathrm{F}, \mathrm{A}, \tilde{\tau})$ is called the soft topological space.

Definition 3.2 [23] If $\tilde{\tau}$ is a soft topology on $(\mathrm{F}, \mathrm{A})$, then the member of $\tilde{\tau}$ is called an open soft set in $(\mathrm{F}, \mathrm{A}, \tilde{\tau})$.

Definition $3.3[6]$ Let $(F, A, \tilde{\tau})$ be a soft topological space and $(\mathrm{G}, \mathrm{B}) \widetilde{\subseteq}(\mathrm{F}, \mathrm{A})$. Then, $(\mathrm{G}, \mathrm{B})$ is said to be closed soft set if the complement of $(G, B)$ is open soft set.

Definition 3.4 [23] A collection $\tilde{\beta}$ of some soft subsets of $(\mathrm{F}, \mathrm{A})$ is called a soft open base or a soft base for some soft topology on $(\mathrm{F}, \mathrm{A})$ if the following conditions hold:
i) $\Phi \in \tilde{\beta}$. 
ii) $\tilde{\beta}=(\mathrm{F}, \mathrm{A})$ ie. for each $\mathrm{e} \in \mathrm{A}$ and $\mathrm{x} \in \mathrm{F}(\mathrm{e})$, there exits $(G, B) \in \tilde{\beta}$ such that $x \in G(e)$, where $\mathrm{B} \subseteq \mathrm{A}$.

iii) If $(G, B),(H, C) \in \tilde{\beta}$ then for each $\mathrm{e} \in \mathrm{B} \cap \mathrm{C}$ and $x \in G(e) \cap H(e)$ there exists $(I, D) \widetilde{\subseteq} \tilde{\beta}$ such that $(\mathrm{I}, \mathrm{D}) \widetilde{\subseteq}(\mathrm{G}, \mathrm{B}) \widetilde{\cap}(\mathrm{H}, \mathrm{C})$ and $\mathrm{x} \in \mathrm{I}(\mathrm{e})$, where $\mathrm{D} \subseteq \mathrm{B} \cap \mathrm{C}$.

Theorem 3.5 [23] Let $\tilde{\beta}$ be a soft base for a soft topology on $(\mathrm{F}, \mathrm{A})$. Suppose $\tilde{\tau}_{\beta}$ consists of soft subset $(G, B)$ of the soft set $(F, A)$ for which corresponding to each $e \in B$ and $x \in G(e)$ there exists $(\mathrm{H}, \mathrm{C}) \in \tilde{\beta}$ such that $(\mathrm{H}, \mathrm{C}) \widetilde{\subseteq}(\mathrm{G}, \mathrm{B})$ and $\mathrm{x} \in \mathrm{H}(\mathrm{e})$, where $\mathrm{C} \subseteq \mathrm{B}$. Then $\tilde{\tau}_{\beta}$ is a soft topology on $(\mathrm{F}, \mathrm{A})$.

Definition 3.6 [23] Suppose $\tilde{\beta}$ is a soft base for a soft topology on $(\mathrm{F}, \mathrm{A})$. Then $\tilde{\tau}_{\beta}$, which is described in Theorem 3.5, is called the soft topology generated by $\tilde{\beta}$ and $\tilde{\beta}$ is called the soft base for $\tilde{\tau}_{\beta}$.

Theorem 3.7 [23] Let $\tilde{\beta}$ be a soft base for a soft topology on $(\mathrm{F}, \mathrm{A})$. Then $(\mathrm{G}, \mathrm{B}) \in \tilde{\tau}_{\beta}$ if and only if $(\mathrm{G}, \mathrm{B})=\widetilde{\mathrm{U}}_{\alpha \in \Lambda}\left(G_{\alpha}, B_{\alpha}\right)$ where $\left(G_{\alpha}, B_{\alpha}\right) \in \tilde{\beta}$ for each $\alpha \in \Lambda, \Lambda$ an index set.

Theorem 3.6 Let $(\mathrm{F}, \mathrm{A}, \tilde{\tau})$ be soft topological space. Suppose that $\tilde{\mathcal{C}}$ is a collection of open soft sets of $(F, A)$ such that for each open $(G, B)$ of $(F, A)$ and each $G(b)$ in $(G, B)$, there is an element $(H, C)$ of $\tilde{\mathcal{C}}$ such that $G(b) \in(H, C) \widetilde{\subseteq}(G, B)$. Then $\tilde{\mathcal{C}}$ is a soft basis for the soft topology $\tilde{\tau}$ on $(\mathrm{F}, \mathrm{A})$.

Proof. We must show that $\tilde{\mathcal{C}}$ is a basis.

1. $\Phi \in \tilde{\mathcal{C}} ;$

2. For $F(x)$ in $(F, A)$, since $(F, A)$ is itself an open soft set, there is by hypothesis an element $(\mathrm{G}, \mathrm{B})$ of $\tilde{\mathcal{C}}$ such that $\mathrm{F}(\mathrm{x}) \in(\mathrm{G}, \mathrm{B}) \widetilde{\subseteq}(\mathrm{F}, \mathrm{A})$; then $(\mathrm{F}, \mathrm{A})=\tilde{\mathcal{C}}$.

3. Let $\mathrm{F}(\mathrm{x}) \in\left(G_{1}, B_{1}\right) \widetilde{\cap}\left(G_{2}, B_{2}\right)$ where $\left(G_{1}, B_{1}\right)$, $\left(G_{2}, B_{2}\right) \in \tilde{\mathcal{C}}$. Since $\left(G_{1}, B_{1}\right)$ and $\left(G_{2}, B_{2}\right)$ are open soft sets, so is $\left(G_{1}, B_{1}\right) \widetilde{\cap}\left(G_{2}, B_{2}\right)$. Therefore, there exists by hypothesis an element $\left(G_{3}, B_{3}\right)$ in $\tilde{\mathcal{C}}$ such that $\mathrm{F}(\mathrm{x}) \in\left(G_{3}, B_{3}\right) \widetilde{\widetilde{\simeq}}\left(G_{1}, B_{1}\right) \widetilde{\cap}\left(G_{2}, B_{2}\right)$. Let $\tilde{\tau}$ be the collection of open soft sets of $(\mathrm{F}, \mathrm{A})$; we must show that the topology $\tilde{\tau}$ generated by $\mathrm{C}$ equals the topology $\tilde{\tau}$. First, note that if $(U, C)$ belong to $\tilde{\tau}$ and if $\mathrm{U}(\mathrm{c}) \in(\mathrm{U}, \mathrm{C})$, then there is $\mathrm{y}$ hypothesis an element $(\mathrm{G}, \mathrm{B})$ of $\tilde{\mathcal{C}}$ such that $\mathrm{U}(\mathrm{c}) \in(\mathrm{G}, \mathrm{B}) \widetilde{\widetilde{ }}(\mathrm{U}, \mathrm{C})$. It follows that $(U, C)$ belongs to the topology $\tilde{\tau}$, then $\left(\mathrm{W}, \mathrm{B}^{\prime}\right)$ equals a union of elements of $\tilde{\mathcal{C}}$, by the Theorem 3.5. Since each element of $C$ belongs to $\tilde{\tau}$ and $\tilde{\tau}$ is a topology. $\left(\mathrm{W}, \mathrm{B}^{\prime}\right)$ also belongs to $\tilde{\tau}$.

Theorem 3.9 Let $(\mathrm{F}, \mathrm{A}, \tilde{\tau})$ be a soft topological space. $\tilde{\beta}$ is a soft base if and only if

$1 \tilde{\beta} \widetilde{\simeq}$,

2 For all $(\mathrm{G}, \mathrm{B}) \in \widetilde{\tau},(\mathrm{G}, \mathrm{B})=\widetilde{\mathrm{U}}_{\text {for some }}(H, C) \in \widetilde{\beta}(H, C)$.

Proof $(\Rightarrow) 1$ By Definition 3.4.

2 Let $(\mathrm{G}, \mathrm{B}) \in \tilde{\tau}$. If $(\mathrm{G}, \mathrm{B})=\Phi$ then $(G, B)=$ $\widetilde{\mathrm{U}}_{i \in \varnothing}\left(H_{i}, C_{i}\right)$. If $(\mathrm{G}, \mathrm{B}) \neq \Phi$ then for all $\mathrm{x} \in \mathrm{G}(\mathrm{e})$ there exists a soft set $(H, C) \in \tilde{\beta}$ such that $(H, C) \widetilde{\subseteq}(G, B)$ and $\quad \mathrm{x} \in \mathrm{H}(\mathrm{e}) \quad$ where $\quad \mathrm{C} \subset \mathrm{B}$ then $(\mathrm{G}, \mathrm{B})=\widetilde{\mathrm{U}}_{\text {for some }}(\mathrm{H}, \mathrm{C}) \in \widetilde{\beta}(H, C)$.

(朱 i $\Phi=\widetilde{\mathbf{U}}_{i \in \emptyset}\left(H_{i}, C_{i}\right)$.

ii Since $\tilde{\tau}$ is a soft topology then $(\mathrm{F}, \mathrm{A}) \in \tilde{\tau}$ and by (2) $(\mathrm{F}, \mathrm{A})=\widetilde{U} \tilde{\beta}$.

iii Let $\left(G_{1}, B_{1}\right),\left(G_{2}, B_{2}\right) \in \tilde{\beta} \quad$ then $\left(G_{1}, B_{1}\right)$, $\left(G_{2}, B_{2}\right) \in \tilde{\tau}$ since $\left(G_{1}, B_{1}\right) \widetilde{n}\left(G_{2}, B_{2}\right) \in \tilde{\tau}$ then by $\left(G_{1}, B_{1}\right) \widetilde{\cap}\left(G_{2}, B_{2}\right)=\widetilde{\cup}_{\text {for some }(\mathrm{H}, \mathrm{C}) \in \widetilde{\beta}}(H, C)$. Then for $e \in B_{1} \cap B_{2}$ that $(\mathrm{H}, \mathrm{C}) \widetilde{\subseteq}\left(G_{1}, B_{1}\right) \widetilde{\cap}\left(G_{2}, B_{2}\right) \quad$ and $\mathrm{x} \in \mathrm{H}(\mathrm{e})$ where $\mathrm{C} \subset B_{1} \cap B_{2}$.

\section{Main Results}

\subsection{Soft Intervals}

Definition 4.1 Let $\mathrm{R}$ be a soft set relation on a soft set $(\mathrm{F}, \mathrm{A})$. If for no $\mathrm{a} \in \mathrm{A}, \mathrm{F}(\mathrm{a})$ the soft set relation $\mathrm{F}(\mathrm{a}) \mathrm{RF}(\mathrm{a})$ hold, the soft set relation $\mathrm{R}$ is called nonreflexive.

Definition 4.2 A soft set relation $\mathrm{R}$ on a soft set $(\mathrm{F}, \mathrm{A})$ is called simple order soft set relation if it is comparable, nonreflexive and transitive. $(\mathrm{F}, \mathrm{A})$ is called a simple ordered soft set a the simple order 
soft set relation $R$.

Definition 4.3 Let $\leq$ be a soft set relation on $(\mathrm{F}, \mathrm{A})$, then restriction of a soft set relation $\leq$ to a soft subset $(G, B)$ is defined as follows:

We denote $G(a) \leq(G, B) G(b)$ : if and only if $F(a) \leq F(b)$ for all $\mathrm{a}, \mathrm{b} \in \mathrm{B}$.

Example 4.4 Let $\mathrm{U}=\left\{c_{1}, c_{2}, c_{3}, c_{4}, c_{5}, c_{6}\right\}$ be a universe and $\mathrm{A}=\left\{a_{1}, a_{2}, a_{3}\right\}$ be a parameter set. $\mathrm{F}\left(a_{1}\right)=\left\{c_{1}, c_{2}\right\}$, $\mathrm{F}\left(a_{2}\right)=\left\{c_{3}, c_{4}, c_{5}\right\}, \quad \mathrm{F}\left(a_{3}\right)=\left\{c_{5}\right\} ; \mathrm{B}=\left\{a_{1}, a_{2}\right\}, \quad \mathrm{G}\left(a_{1}\right)=\left\{c_{1}\right\}$, $\mathrm{G}\left(a_{2}\right)=\left\{c_{3}, c_{5}\right\}$. Then $(\mathrm{G}, \mathrm{B}) \widetilde{\subseteq}(\mathrm{F}, \mathrm{A})$.

$\leq=\left\{\mathrm{F}\left(a_{1}\right) \times \mathrm{F}\left(a_{2}\right), \mathrm{F}\left(a_{2}\right) \times \mathrm{F}\left(a_{3}\right)\right\}=\left\{\left(c_{1}, c_{3}\right),\left(c_{1}, c_{4}\right),\left(c_{1}, c_{5}\right)\right.$, $\left.\left(c_{2}, c_{3}\right),\left(c_{2}, c_{4}\right),\left(c_{2}, c_{5}\right),\left(c_{4}, c_{5}\right),\left(c_{5}, c_{5}\right)\right\}$.

Then $\leq(\mathrm{G}, \mathrm{B})=\left\{\mathrm{G}\left(a_{1}\right) \times \mathrm{G}\left(a_{2}\right)\right\}=\left\{\left(c_{1}, c_{3}\right),\left(c_{1}, c_{5}\right)\right\}$.

Definition 4.5 Suppose that $(\mathrm{F}, \mathrm{A})$ is a soft set having a simple order soft set relation $<$ and $\mathrm{F}(\mathrm{a})$ and $F(b)$ be elements of (F,A) such that $F(a)<F(b)$. Then we can define following four soft subsets of $(\mathrm{F}, \mathrm{A})$ which are called soft intervals (respectively; soft open interval, soft half open intervals, soft closed interval) determined by $\mathrm{F}(\mathrm{a})$ and $\mathrm{F}(\mathrm{b})$ :

a Soft Open Interval: The soft open interval is a soft subset $(\mathrm{G}, \mathrm{B})$ of $(\mathrm{F}, \mathrm{A})$ where $\mathrm{B}=\{\mathrm{x} \mid$ $\mathrm{F}(\mathrm{a})<\mathrm{F}(\mathrm{x})<\mathrm{F}(\mathrm{b})\}, \quad \mathrm{G}=\left.\mathrm{F}\right|_{B}$ and denoted by $(\mathrm{F}(\mathrm{a}), \mathrm{F}(\mathrm{b}))=\{\mathrm{F}(\mathrm{x}) \mid \mathrm{F}(\mathrm{a})<\mathrm{F}(\mathrm{x})<\mathrm{F}(\mathrm{b})\}$.

b Soft Half Open Interval: The soft open interval is a soft subset $(\mathrm{G}, \mathrm{B})$ of $(\mathrm{F}, \mathrm{A})$ where $\mathrm{B}=\{\mathrm{x} \mid \mathrm{F}(\mathrm{a})<\mathrm{F}(\mathrm{x})<\mathrm{F}(\mathrm{b}) \quad$ or $\quad \mathrm{F}(\mathrm{x})=\mathrm{F}(\mathrm{b})\}, \quad \mathrm{G}=\left.\mathrm{F}\right|_{B} \quad$ and denoted by $(\mathrm{F}(\mathrm{a}), \mathrm{F}(\mathrm{b})]=\{\mathrm{F}(\mathrm{x}) \mid \mathrm{F}(\mathrm{a})<\mathrm{F}(\mathrm{x})<\mathrm{F}(\mathrm{b}) \quad$ or $\mathrm{F}(\mathrm{x})=\mathrm{F}(\mathrm{b})\}$.

c Soft Half Open Interval: The soft open interval is a soft subset $(\mathrm{G}, \mathrm{B})$ of $(\mathrm{F}, \mathrm{A})$ where $\mathrm{B}=\{\mathrm{x} \mid$ $\mathrm{F}(\mathrm{a})<\mathrm{F}(\mathrm{x})<\mathrm{F}(\mathrm{b})$, or $\mathrm{F}(\mathrm{x})=\mathrm{F}(\mathrm{a})\}, \mathrm{G}=\left.\mathrm{F}\right|_{B}$ and denoted by $[\mathrm{F}(\mathrm{a}), \mathrm{F}(\mathrm{b}))=\{\mathrm{F}(\mathrm{x}) \mid \mathrm{F}(\mathrm{a})<\mathrm{F}(\mathrm{x})<\mathrm{F}(\mathrm{b})$ or $\mathrm{F}(\mathrm{x})=\mathrm{F}(\mathrm{a})\}$.

d Soft Closed Interval: The soft open interval is a soft subset $(G, B)$ of $(F, A)$ where $B=\{x \mid F(a)<F(x)<F(b)$ or $\mathrm{F}(\mathrm{x})=\mathrm{F}(\mathrm{a})$ or $\mathrm{F}(\mathrm{x})=\mathrm{F}(\mathrm{b})\}, \mathrm{G}=\left.\mathrm{F}\right|_{B}$ and denoted by $[F(a), F(b)]=\{F(x) \mid \quad F(a)<F(x)<F(b) \quad$ or $\quad F(x)=F(a)$ or $\mathrm{F}(\mathrm{x})=\mathrm{F}(\mathrm{b})\}$.
These are the soft intervals on an arbitrary simple ordered soft set.

Remark 4.6 If we take (F,A) with a partially order soft set relation $\leq$, instead of a simple order soft set relation $<$, we can write previous soft intervals as follows:

a $(\mathrm{F}(\mathrm{a}), \mathrm{F}(\mathrm{b}))=\{\mathrm{F}(\mathrm{x}) \mid \mathrm{F}(\mathrm{a}) \leq \mathrm{F}(\mathrm{x}) \leq \mathrm{F}(\mathrm{b})$ and $\mathrm{F}(\mathrm{x}) \neq \mathrm{F}(\mathrm{a})$ and $\mathrm{F}(\mathrm{x}) \neq \mathrm{F}(\mathrm{b})\}$;

b $(\mathrm{F}(\mathrm{a}), \mathrm{F}(\mathrm{b})]=\{\mathrm{F}(\mathrm{x}) \mid \mathrm{F}(\mathrm{a}) \leq \mathrm{F}(\mathrm{x}) \leq \mathrm{F}(\mathrm{b})$ and $\mathrm{F}(\mathrm{x}) \neq \mathrm{F}(\mathrm{a})\} ;$

c $[\mathrm{F}(\mathrm{a}), \mathrm{F}(\mathrm{b}))=\{\mathrm{F}(\mathrm{x}) \mid \mathrm{F}(\mathrm{a}) \leq \mathrm{F}(\mathrm{x}) \leq \mathrm{F}(\mathrm{b})$ and $\mathrm{F}(\mathrm{x}) \neq \mathrm{F}(\mathrm{b})\}$;

$d[F(a), F(b)]=\{F(x) \mid F(a) \leq F(x) \leq F(b)\}$.

Example 4.7 Let $\mathrm{U}=\left\{h_{1}, h_{2}, h_{3}, h_{4}, h_{5}, h_{6}\right\}$ be the universe set and $\mathrm{E}=\left\{e_{1}, e_{2}, e_{3}, e_{4}, e_{5}\right\}$ be the parameter set. Lets define a soft set (F,E) such that $\mathrm{F}\left(e_{1}\right)=\left\{h_{2}, h_{3}\right\}, \quad \mathrm{F}\left(e_{2}\right)=\left\{h_{2}, h_{3}, h_{5}\right\}, \quad \mathrm{F}\left(e_{3}\right)=\left\{h_{1}, h_{4}\right\}$, $\mathrm{F}\left(e_{4}\right)=\left\{h_{1}\right\}, \quad \mathrm{F}\left(e_{5}\right)=\left\{h_{1}, h_{2}, h_{6}\right\}$. Consider a soft set relation on $(\mathrm{F}, \mathrm{E})$ defined by $\Leftrightarrow=\{\mathrm{F}(\mathrm{e} 3) \times \mathrm{F}(\mathrm{e} 1)$, $\mathrm{F}\left(\mathrm{e}_{3}\right) \times \mathrm{F}\left(\mathrm{e}_{4}\right), \quad \mathrm{F}\left(\mathrm{e}_{3}\right) \times \mathrm{F}\left(\mathrm{e}_{5}\right), \quad \mathrm{F}\left(\mathrm{e}_{3}\right) \times \mathrm{F}\left(\mathrm{e}_{2}\right), \quad \mathrm{F}\left(\mathrm{e}_{1}\right) \times \mathrm{F}\left(\mathrm{e}_{4}\right)$, $\mathrm{F}\left(\mathrm{e}_{1}\right) \times \mathrm{F}\left(\mathrm{e}_{5}\right), \quad \mathrm{F}\left(\mathrm{e}_{1}\right) \times \mathrm{F}\left(\mathrm{e}_{2}\right), \quad \mathrm{F}\left(\mathrm{e}_{4}\right) \times \mathrm{F}\left(\mathrm{e}_{5}\right), \quad \mathrm{F}\left(\mathrm{e}_{4}\right) \times \mathrm{F}\left(\mathrm{e}_{2}\right)$, $\left.\mathrm{F}\left(\mathrm{e}_{5}\right) \times \mathrm{F}\left(\mathrm{e}_{2}\right)\right\}$. Soft set relation $<$ is comparable, nonreflexive, transitive so it is simple order soft set relation.

All soft closed intervals are as follows:

$\left[\mathrm{F}\left(e_{3}\right), \mathrm{F}\left(e_{1}\right)\right] \quad\left[\mathrm{F}\left(e_{3}\right), \mathrm{F}\left(e_{4}\right)\right]$

$\left[\mathrm{F}\left(e_{3}\right), \mathrm{F}\left(e_{5}\right)\right] \quad\left[\mathrm{F}\left(e_{3}\right), \mathrm{F}\left(e_{2}\right)\right]$

$\left[\mathrm{F}\left(e_{1}\right), \mathrm{F}\left(e_{4}\right)\right] \quad\left[\mathrm{F}\left(e_{1}\right), \mathrm{F}\left(e_{5}\right)\right]$

$\left[\mathrm{F}\left(e_{1}\right), \mathrm{F}\left(e_{2}\right)\right] \quad\left[\mathrm{F}\left(e_{4}\right), \mathrm{F}\left(e_{5}\right)\right]$

$\left[\mathrm{F}\left(e_{4}\right), \mathrm{F}\left(e_{2}\right)\right] \quad\left[\mathrm{F}\left(e_{5}\right), \mathrm{F}\left(e_{2}\right)\right]$

All these soft intervals are, soft sets and soft intervals can be expressed in the matrix form given in [7] as in Example 4.8. Since the matrix representations of soft sets are effective, the soft intervals are more functional with these matrix representations.

Example 4.8 Let us consider the Example 4.7 and 
consider two of soft closed intervals for example, $\left[\mathrm{F}\left(e_{3}\right), \mathrm{F}\left(e_{1}\right)\right]$ and $\left[\mathrm{F}\left(e_{3}\right), \mathrm{F}\left(e_{4}\right)\right]$. The matrices [aij] and $\left[\mathrm{b}_{\mathrm{ij}}\right]$ for the soft closed intervals $\left[\mathrm{F}\left(e_{3}\right), \mathrm{F}\left(e_{1}\right)\right]$ and $\left[\mathrm{F}\left(e_{3}\right), \mathrm{F}\left(e_{4}\right)\right]$ are writtten as respectively.

$$
\left[a_{i j}\right]=\left[\begin{array}{cc}
0 & 1 \\
1 & 0 \\
1 & 0 \\
0 & 1 \\
0 & 0 \\
0 & 0 \\
0 & 0
\end{array}\right] \quad\left[b_{i j}\right]=\left[\begin{array}{ccc}
0 & 1 & 1 \\
1 & 0 & 0 \\
1 & 0 & 0 \\
0 & 1 & 0 \\
0 & 0 & 0 \\
0 & 0 & 0 \\
0 & 0 & 0
\end{array}\right]
$$

In addition to previous matrix form of a soft interval, we also can represent all soft closed intervals in a tabular form, which is similar as in [31], whose columns stand for intervals and rows stand for the elements of universe. To express that tabular representation of all soft closed intervals we will use $\alpha \mathrm{s}$ for the soft closed intervals, after arbitrary ordering on soft closed intervals and use an interval number $c_{i j}=\left[a_{i j}, b_{i j}\right]$, where $c_{i j}$ are entries in the tabular representation. For a soft closed interval $\alpha_{j}=[\mathrm{F}(\mathrm{a}), \mathrm{F}(\mathrm{b})]$, if $h_{i} \in \mathrm{F}(\mathrm{a})$ then $a_{i j}=1$, otherwise $a_{i j}=0$;

if $h_{i} \in \mathrm{F}(\mathrm{b})$ then $b_{i j}=1$, otherwise $b_{i j}=0$; with $1 \leq \mathrm{j} \leq \mathrm{n}$ where $\mathrm{n}$ is the number of all soft closed intervals.

Example 4.9 Let us consider the Example 4.7 and write them in the tabular form described above. Let

$\alpha_{1}=\left[\mathrm{F}\left(e_{3}\right), \mathrm{F}\left(e_{1}\right)\right] \quad \alpha_{6}=\left[\mathrm{F}\left(e_{1}\right), \mathrm{F}\left(e_{5}\right)\right]$

$\alpha_{2}=\left[\mathrm{F}\left(e_{3}\right), \mathrm{F}\left(e_{4}\right)\right] \quad \alpha_{7}=\left[\mathrm{F}\left(e_{1}\right), \mathrm{F}\left(e_{2}\right)\right]$

$\alpha_{3}=\left[\mathrm{F}\left(e_{3}\right), \mathrm{F}\left(e_{5}\right)\right] \quad \alpha_{8}=\left[\mathrm{F}\left(e_{4}\right), \mathrm{F}\left(e_{5}\right)\right]$

$\alpha_{4}=\left[\mathrm{F}\left(e_{3}\right), \mathrm{F}\left(e_{2}\right)\right] \quad \alpha_{9}=\left[\mathrm{F}\left(e_{4}\right), \mathrm{F}\left(e_{2}\right)\right]$

$\alpha_{5}=\left[\mathrm{F}\left(e_{1}\right), \mathrm{F}\left(e_{4}\right)\right] \quad \alpha_{10}=\left[\mathrm{F}\left(e_{5}\right), \mathrm{F}\left(e_{2}\right)\right]$

then the tabular representation of all soft closed intervals is following
Table 1: Tabular representation of a soft closed intervals of a soft set $(F, E)$

\begin{tabular}{ccccccccccc}
\hline \hline & $\alpha_{1}$ & $\alpha_{2}$ & $\alpha_{3}$ & $\alpha_{4}$ & $\alpha_{5}$ & $\alpha_{6}$ & $\alpha_{7}$ & $\alpha_{8}$ & $\alpha_{9}$ & $\alpha_{10}$ \\
\hline$h_{1}$ & {$[1,0]$} & {$[1,1]$} & {$[1,1]$} & {$[1,0]$} & {$[0,1]$} & {$[0,1]$} & {$[0,0]$} & {$[1,1]$} & {$[1,0]$} & {$[1,0]$} \\
$h_{2}$ & {$[0,1]$} & {$[0,0]$} & {$[0,1]$} & {$[0,1]$} & {$[1,0]$} & {$[1,1]$} & {$[1,1]$} & {$[0,1]$} & {$[0,1]$} & {$[1,1]$} \\
$h_{3}$ & {$[0,1]$} & {$[0,0]$} & {$[0,0]$} & {$[0,1]$} & {$[1,0]$} & {$[1,0]$} & {$[1,1]$} & {$[0,0]$} & {$[0,1]$} & {$[0,1]$} \\
$h_{4}$ & {$[1,0]$} & {$[1,0]$} & {$[1,0]$} & {$[1,0]$} & {$[0,0]$} & {$[0,0]$} & {$[0,0]$} & {$[0,0]$} & {$[0,0]$} & {$[0,0]$} \\
$h_{5}$ & {$[0,0]$} & {$[0,0]$} & {$[0,0]$} & {$[0,1]$} & {$[0,0]$} & {$[0,0]$} & {$[0,1]$} & {$[0,0]$} & {$[0,1]$} & {$[0,1]$} \\
$h_{6}$ & {$[0,0]$} & {$[0,0]$} & {$[0,1]$} & {$[0,0]$} & {$[0,0]$} & {$[0,1]$} & {$[0,0]$} & {$[0,1]$} & {$[0,0]$} & {$[1,0]$} \\
\hline
\end{tabular}

Definition 4.10 Let (F,A) be an simple ordered soft set with a soft set relation $<$ and $F(a)$ be in $(F, A)$. Then there are four soft subsets of $(\mathrm{F}, \mathrm{A})$ which are called soft rays determined $\mathrm{F}(\mathrm{a})$. They are following:

A $\left(F(a),{ }^{*}\right)=\{F(x) \mid F(a)<F(x)\}$, called soft open ray

B $(*, F(a))=\{F(x) \mid F(x)<F(a)\}$, called soft open ray

C $\left[F(a),{ }^{*}\right)=\{F(x) \mid F(a)<F(x)$ or $F(a)=F(x)\}$, called soft closed ray

D $(*, F(a))=\{\mathrm{F}(\mathrm{x}) \mid \mathrm{F}(\mathrm{x})<\mathrm{F}(\mathrm{a})$ or $\mathrm{F}(\mathrm{a})=\mathrm{F}(\mathrm{x})\}$, called soft closed ray.

Theorem 4.11 Soft intervals on a simple ordered soft set with a soft set relation $<$ which has a type $(\mathrm{F}(\mathrm{a}), \mathrm{F}(\mathrm{b})]$ are directed soft sets.

Proof. Let $(\mathrm{G}, \mathrm{B})$ finite soft subset of soft interval $(\mathrm{F}(\mathrm{a}), \mathrm{F}(\mathrm{b})]$. Since the soft set relation $<$ is comparable and $(\mathrm{G}, \mathrm{B})$ is finite soft set there exists an upper bound for $b_{0} \in \mathrm{B}, \mathrm{G}\left(b_{0}\right)$. Therefore $(\mathrm{F}(\mathrm{a}), \mathrm{F}(\mathrm{b})]$ is a directed soft set.

\subsection{Soft Order Topology}

In this section we will use notions of soft interval and soft base to construct the Soft Order Topology.

Theorem 4.12 Let (F, A) be a soft set with a simple order soft set relation; assume that $(\mathrm{F}, \mathrm{A})$ has more then one element. Let $\tilde{\beta}$ be a collection of all soft subsets of $(F, A)$ of the following types:

(1) $\Phi$,

(2) All soft open intervals $(\mathrm{F}(\mathrm{a}), \mathrm{F}(\mathrm{b}))$ in $(\mathrm{F}, \mathrm{A})$,

(3) All soft intervals of the form $\left[\mathrm{F}\left(a_{0}\right), \mathrm{F}(\mathrm{b})\right)$, where $\mathrm{F}\left(a_{0}\right)$ is the least element (if any) of $(\mathrm{F}, \mathrm{A})$, 
(4) All soft intervals of the form $\left(\mathrm{F}(\mathrm{a}), \mathrm{F}\left(b_{0}\right)\right]$, where $\mathrm{F}\left(a_{0}\right)$ is the greatest element (if any) of $(\mathrm{F}, \mathrm{A})$.

Then the collection $\tilde{\beta}$ is a soft basis for a soft topology on (F, A).

If $(\mathrm{F}, \mathrm{A})$ has no least element, there is no soft set in type (3), and if (F, A) has no greatest element, there is no soft set in type (4).

Proof. Lets check $\tilde{\beta}$ satisfies the requirements for being a soft basis given in the Definition 3.4.

(1) $\Phi \in \tilde{\beta}$.

(2) Take $\mathrm{e} \in \mathrm{A}$ and $\mathrm{x} \in \mathrm{F}(\mathrm{e})$. By comparability there exists a soft interval $(G, B)$, where $x \in B \subseteq A$ and $x \in G(e)$.

(3) Let $(\mathrm{G}, \mathrm{B}),(\mathrm{H}, \mathrm{C}) \in \tilde{\beta}$, where $(\mathrm{G}, \mathrm{B})=(\mathrm{F}(\mathrm{a}), \mathrm{F}(\mathrm{b}))$, $(\mathrm{H}, \mathrm{C})=(\mathrm{F}(\mathrm{c}), \mathrm{F}(\mathrm{d}))$. Then

$$
\begin{aligned}
& (G, B) \widetilde{\cap}(H, C)=(F(a), F(b)) \widetilde{\cap}(F(c), F(d)) \\
& \Phi, \quad \begin{aligned}
& F(a)<F(b) \\
& \Phi, F(d)<F(a) \\
&(F(c), F(b)) F(c)<F(b) \\
&(F(a), F(d)) F(a)<F(d) \\
&(F(a), F(b)) F(a)<F(c), F(b)<F(d) \\
&(F(c), F(d)) F(c)<F(a), F(d)<F(b) \\
&\left(F\left(a^{\prime}\right), F\left(d^{\prime}\right)\right)
\end{aligned}
\end{aligned}
$$

Definition 4.13 The soft topology mentioned above is called Soft Order Topology.

Example 4.14 Let $\mathrm{U}=\left\{c_{1}, c_{2}, c_{3}, c_{4}, c_{5}, c_{6}\right\}$ be a universe and $\mathrm{A}=\left\{a_{1}, a_{2}, a_{3}\right\}$ be a parameter set. $\mathrm{F}\left(a_{1}\right)=\left\{c_{1}, c_{2}\right\}, \quad \mathrm{F}\left(a_{2}\right)=\left\{c_{2}\right\}, \quad \mathrm{F}(\mathrm{a} 3)=\left\{c_{4}, c_{5}, c_{6}\right\} ;<=$ $\left\{\mathrm{F}\left(a_{1}\right) \times \mathrm{F}\left(a_{2}\right), \quad \mathrm{F}\left(a_{2}\right) \times \mathrm{F}(\mathrm{a} 3), \quad \mathrm{F}\left(a_{1}\right) \times \mathrm{F}\left(a_{3}\right)\right\}$. Then the soft order topology is;

$\tilde{\tau}=\left\{\Phi, \quad\left[\mathrm{F}\left(a_{1}\right), \mathrm{F}\left(a_{2}\right)\right), \quad\left(\mathrm{F}\left(a_{1}\right), \mathrm{F}\left(a_{2}\right)\right), \quad\left[\mathrm{F}\left(a_{1}\right), \mathrm{F}\left(a_{3}\right)\right)\right.$, $\left(\mathrm{F}\left(a_{1}\right), \mathrm{F}\left(a_{3}\right)\right), \quad\left[\mathrm{F}\left(a_{1}\right), \mathrm{F}\left(a_{3}\right)\right], \quad\left(\mathrm{F}\left(a_{2}\right), \mathrm{F}\left(a_{3}\right)\right)$, $\left.\left(\mathrm{F}\left(a_{2}\right), \mathrm{F}\left(a_{3}\right)\right]\right\}=\left\{\Phi,(\mathrm{F}, \mathrm{A}),\left\{\mathrm{F}\left(a_{2}\right)\right\},\left\{\mathrm{F}\left(a_{1}\right), \mathrm{F}\left(a_{2}\right)\right\},\left\{\mathrm{F}\left(a_{2}\right)\right.\right.$, $\left.\left.\mathrm{F}\left(a_{3}\right)\right\},\left\{\mathrm{F}\left(a_{1}\right)\right\},\left\{\mathrm{F}\left(a_{3}\right)\right\}\right\}$.

Example 4.15 Let $\mathrm{U}=\mathrm{R}^{+}, \mathrm{A}=\mathrm{Z}^{+}$and $(\mathrm{F}, \mathrm{A})$ be a soft set where $F(a)=(1, a]$ for all $a \in A$. Lets define simple order on $(\mathrm{F}, \mathrm{A})$ as follows: $\mathrm{F}(\mathrm{a})<\mathrm{F}(\mathrm{b}): \Leftrightarrow \mathrm{a}<\mathrm{b}: \Leftrightarrow(1, \mathrm{a}] \subseteq(1, \mathrm{~b}]$.

$F(1)$ is the smallest element, so

$\tilde{\beta}=\{[\mathrm{F}(1), \mathrm{F}(\mathrm{a})),(\mathrm{F}(\mathrm{a}), \mathrm{F}(\mathrm{b})) \mid \mathrm{F}(\mathrm{a}), \mathrm{F}(\mathrm{b})$ in $(\mathrm{F}, \mathrm{A})\}$ is a soft basis for the soft order topology on $(\mathrm{F}, \mathrm{A})$.

Example 4.16 Let $\mathrm{U}=(-\infty, 0]$ be the initial universe and let $\mathrm{A}=\mathrm{Z}^{-}$be the parameter set and let $(\mathrm{F}, \mathrm{A})$ be a soft set, defined by $(\mathrm{F}, \mathrm{A})=\{\mathrm{F}(\mathrm{a})=(\mathrm{a}, 0] \mid \mathrm{a} \in \mathrm{A}\}$. Consider the soft set relation $<$ on $(\mathrm{F}, \mathrm{A})$, which is defined by $F(a)<F(b): \Leftrightarrow a<b . \quad(F, A)$ is a simple ordered soft set with the relation $<$. By examining the soft subsets of $(\mathrm{F}, \mathrm{A}), \mathrm{F}(0)$ is the biggest element.

$\tilde{\beta}=\{(\mathrm{F}(\mathrm{a}), \mathrm{F}(0)],(\mathrm{F}(\mathrm{a}), \mathrm{F}(\mathrm{b})) \mid \mathrm{F}(\mathrm{a}), \mathrm{F}(\mathrm{b})$ in $(\mathrm{F}, \mathrm{A})\}$

is a basis for the soft order topology.

Definition 4.17 Let $(\mathrm{F}, \mathrm{A}, \tilde{\tau})$ be a soft topological space and $\tilde{\mathcal{S}}$ be a collection of nonnull soft open subsets of $(\mathrm{F}, \mathrm{A})$. If finite intersection of the elements of $\tilde{\mathcal{S}}$ is a base for $\tilde{\tau}$ then $\tilde{\mathcal{S}}$ is called soft subbase, ie.;

$\widetilde{\mathcal{B}}_{\tilde{S}}=\left\{\widetilde{\cap}_{j \in J}\left(S_{j}, A_{j}\right) \mid \mathrm{J}\right.$ is a finite and for all $\mathrm{j} \in \mathrm{J},\left(S_{j}, A_{j}\right) \in$ $\tilde{\mathcal{S}}\}$

Theorem 4.18 Let (F,A) nonnull soft set and let $\tilde{\mathcal{S}}$ be a collection of soft subsets of $(\mathrm{F}, \mathrm{A})$. Then there exists a soft topology on $(\mathrm{F}, \mathrm{A})$ which has as a subbase $\tilde{\mathcal{S}}$.

Proof. Lets show that $\widetilde{\mathcal{B}}_{\tilde{\mathcal{S}}}=\left\{\widetilde{\mathrm{n}}_{j \in J}\left(S_{j}, A_{j}\right) \mid \mathrm{J}\right.$ is a finite and for all $\left.\mathrm{j} \in \mathrm{J},\left(S_{j}, A_{j}\right) \in \tilde{\mathcal{S}}\right\}$ satisfies the conditions of being a soft base

$\mathbf{1}(\mathrm{F}, \mathrm{A})=\widetilde{\mathrm{n}}_{j \in J}\left(S_{j}, A_{j}\right)$ then $(F, A) \in \widetilde{\mathcal{B}}_{\tilde{\delta}}$

2 Let $\left(G_{1}, B_{1}\right),\left(G_{2}, B_{2}\right) \in \widetilde{\mathcal{B}}_{\tilde{\mathcal{S}}} \Rightarrow$ If $\left(G_{1}, B_{1}\right) \widetilde{\cap}\left(G_{2}, B_{2}\right)=\Phi$ $\Rightarrow\left(G_{1}, B_{1}\right) \widetilde{\cap}\left(G_{2}, B_{2}\right)=\widetilde{\mathrm{U}}_{j \in \varnothing}\left(G_{j}, B_{j}\right)$.

If $\quad\left(G_{1}, B_{1}\right) \widetilde{\cap}\left(G_{2}, B_{2}\right) \neq \Phi \quad \Rightarrow \quad$ since $\quad\left(G_{1}, B_{1}\right)=$ $\widetilde{\cup}_{j=1}^{n}\left(S_{i}, A_{i}\right), \quad\left(G_{2}, B_{2}\right)=\widetilde{U}_{j=1}^{m}\left(S_{j}, A_{j}\right)$, $\left(G_{1}, B_{1}\right) \widetilde{\cap}\left(G_{2}, B_{2}\right)=\widetilde{\cup}_{j=1}^{n}\left(S_{i}, A_{i}\right) \widetilde{\cap} \widetilde{\cup}_{j=1}^{m}\left(S_{j}, A_{j}\right)=$ $\widetilde{\cup}_{j=1}^{m}\left(S_{j}, A_{j}\right)$. This is finite intersection of elements of 
$\tilde{\mathcal{S}}$ so in $\widetilde{\mathcal{B}}_{\tilde{\mathcal{S}}}$. Therefore $\widetilde{\mathcal{B}}_{\tilde{\mathcal{S}}}$ is a soft base.

Theorem 4.19 Let $(\mathrm{F}, \mathrm{A})$ be a preorder soft set. Then the collection of all soft rays determined by elements of $(\mathrm{F}, \mathrm{A})$ is a soft subbasis for the soft order topology. In other words every basis element in the soft order topology is a finite soft intersection of soft rays.

Proof. Take any soft basis element $(\mathrm{F}(\mathrm{a}), \mathrm{F}(\mathrm{b}))$ of $\mathrm{a}$ soft order topology. We can write;

$(\mathrm{F}(\mathrm{a}), \mathrm{F}(\mathrm{b}))=\left(\mathrm{F}(\mathrm{a}){ }^{*}\right) \widetilde{n}(*, \mathrm{~F}(\mathrm{~b}))$.

So any soft basis element of a soft order topology can be written as a finite soft intersection of a soft rays. Therefore the collection of soft rays forms a soft subbase for the soft order topology.

Definition 4.20 [28] Let $(\mathrm{F}, \mathrm{A})$ be a directed complete partially ordered soft set and $(G, B)$ be a soft subset of $(F, A)$. Then $(G, B)$ is called a Scott open soft set iff the following two conditions are satisfied:

i) $\quad(\mathrm{G}, \mathrm{B})=\uparrow(\mathrm{G}, \mathrm{B})$;

ii) $\sup (\mathrm{D}, \mathrm{C}) \in(\mathrm{G}, \mathrm{B}) \quad$ implies $(D, C) \widetilde{\cap}(G, B) \neq \Phi$ for all directed complete soft sets $(\mathrm{D}, \mathrm{C}) \widetilde{\widetilde{(}}(\mathrm{F}, \mathrm{A})$.

Theorem 4.21 Let $(\mathrm{F}, \mathrm{A})$ be a directed complete partially ordered soft set. Then for any $F(a)$ in $(\mathrm{F}, \mathrm{A}),\left(\mathrm{F}(\mathrm{a}){ }^{*}\right]$ is a soft Scott open set.

\section{Proof.}

i) $\left(\mathrm{F}(\mathrm{a}),{ }^{*}\right]=\uparrow\left(\mathrm{F}(\mathrm{a}),{ }^{*}\right]$;

ii) Take a directed soft set $(\mathrm{D}, \mathrm{C})$ such that $\sup (\mathrm{D}, \mathrm{C}) \in\left(\mathrm{F}(\mathrm{a}), \mathrm{F}\left(b_{0}\right)\right]$. Assume $(\mathrm{D}, \mathrm{C}) \widetilde{\cap}\left(\mathrm{F}(\mathrm{a}),{ }^{*}\right]=\Phi$. Then for all $\mathrm{c} \in \mathrm{C}, \mathrm{D}(\mathrm{c})$ is not in $\left(\mathrm{F}(\mathrm{a}),{ }^{*}\right]$ and since $\sup (D, C)$ is in $\left(F(a),{ }^{*}\right]$, for all $c \in C, D(c) \leq F(a)$. So $\mathrm{F}(\mathrm{a})$ is an upperbound of $(\mathrm{D}, \mathrm{C})$. But this is a contradiction with $\mathrm{F}(\mathrm{a}) \leq \sup (\mathrm{D}, \mathrm{C})$. Therefore $(\mathrm{D}, \mathrm{C}) \widetilde{\cap}\left(\mathrm{F}(\mathrm{a}),{ }^{*}\right] \neq \Phi$

From the Theorem 4.21, we can obtain Soft Scott Topology by using soft interval. Although Soft Order Topology can be obtained by a soft interval,
Soft Scott Topology and Soft Order Topology can be different on the same soft set.

Example 4.22 Let $\mathrm{U}=\left\{c_{1}, c_{2}, c_{3}, c_{4}, c_{5}, c_{6}\right\}$ be the initial universe and let $\mathrm{A}=\left\{a_{1}, a_{2}, a_{3}\right\}$. Consider soft set $(\mathrm{F}, \mathrm{A})$ defined by $\mathrm{F}\left(a_{1}\right)=\left\{c_{1}, c_{2}\right\}, \quad \mathrm{F}\left(a_{2}\right)=\left\{c_{2}\right\}$, $\mathrm{F}\left(a_{3}\right)=\left\{c_{4}, c_{5}, c_{6}\right\}$. Now define a soft set relation $\leq$ on $(\mathrm{F}, \mathrm{A})$ as

$\leq=\quad\left\{\mathrm{F}\left(a_{1}\right) \times \mathrm{F}\left(a_{1}\right), \quad \mathrm{F}\left(a_{2}\right) \times \mathrm{F}\left(a_{2}\right), \quad \mathrm{F}\left(a_{3}\right) \times \mathrm{F}\left(a_{3}\right)\right.$, $\left.\mathrm{F}\left(a_{1}\right) \times \mathrm{F}\left(a_{2}\right), \mathrm{F}\left(a_{2}\right) \times \mathrm{F}\left(a_{3}\right), \mathrm{F}\left(a_{1}\right) \times \mathrm{F}\left(a_{3}\right)\right\}$.

We can also express this relation as $\mathrm{F}\left(a_{1}\right) \leq \mathrm{F}\left(a_{1}\right)$, $\mathrm{F}\left(a_{2}\right) \leq \mathrm{F}\left(a_{2}\right), \quad \mathrm{F}\left(a_{3}\right) \leq \mathrm{F}\left(a_{3}\right), \quad \mathrm{F}\left(a_{1}\right) \leq \mathrm{F}\left(a_{2}\right), \quad \mathrm{F}\left(a_{2}\right) \leq \mathrm{F}\left(a_{3}\right)$, $\mathrm{F}\left(a_{1}\right) \leq \mathrm{F}\left(a_{3}\right)$. $(\mathrm{F}, \mathrm{A})$ is a directed complete partially ordered soft set with the relation $\leq$. We can obtain Soft Scott Topology $\left\{\left(F_{1}, B_{1}\right), \quad\left(F_{2}, B_{2}\right), \quad(\mathrm{F}, \mathrm{A})\right.$, $\Phi\}=\left\{\left(\mathrm{F}\left(a_{1}\right), \mathrm{F}\left(a_{3}\right)\right],\left(\mathrm{F}\left(a_{2}\right), \mathrm{F}\left(a_{3}\right)\right],\left(\mathrm{F}\left(a_{3}\right), \mathrm{F}\left(a_{3}\right)\right], \Phi\right\}$. But the Soft Order Topology on $(\mathrm{F}, \mathrm{A})$ is $\tilde{\tau}=\{\Phi$, $\left[\mathrm{F}\left(a_{1}\right), \mathrm{F}\left(a_{2}\right)\right), \quad\left(\mathrm{F}\left(a_{1}\right), \mathrm{F}\left(a_{2}\right)\right), \quad\left[\mathrm{F}\left(a_{1}\right), \mathrm{F}\left(a_{3}\right)\right)$, $\left(\mathrm{F}\left(a_{1}\right), \mathrm{F}\left(a_{3}\right)\right), \quad\left[\mathrm{F}\left(a_{1}\right), \mathrm{F}\left(a_{3}\right)\right]$, $\left.\left(\mathrm{F}\left(a_{2}\right), \mathrm{F}\left(a_{3}\right)\right),\left(\mathrm{F}\left(a_{2}\right), \mathrm{F}\left(a_{3}\right)\right]\right\}=\left\{\Phi,(F, A),\left\{F\left(a_{2}\right)\right\}\right.$, $\left.\left\{F\left(a_{1}\right), F\left(a_{2}\right)\right\},\left\{F\left(a_{2}\right), F\left(a_{3}\right)\right\},\left\{F\left(a_{1}\right)\right\},\left\{F\left(a_{3}\right)\right\}\right\}$

\section{Conclusion}

In this paper, we gave the definition of soft interval and introduced the soft order topology. Also we proved some results about soft base and soft subbase. Therefore, we obtained an illustration for Soft Scott Topology by using the soft intervals. Following this study, one can investigate these two soft topologies, Soft Scott Topology and Soft Order Topology, in the view of soft separation axioms.

\section{References}

[1] Aktaş, H.; Çağman, N. Soft Sets and Soft Groups, Inform. Sciences. 2007; 177, 2726-2735.

[2] Babitha, K.V.; Sunil, J.J. Soft Set Relations and Functions, Comput. Math. Appl. 2010; 60, 1840-1849.

[3] Babitha, K.V.; Sunil, J.J. Transitive Closures and Ordering on Soft Sets, Comput. Math. Appl. 2011; 62, 2235-2239.

[4] Borah, M.J.; Neog, T.J.; Sut, D.K. Relations on Fuzzy Soft Sets, J. Math. Comput. Sci. 2012; 2(3), 515-534. 
[5] Çağman, N.; Citak, F.; Enginoğlu, S. Fuzzy parametrized fuzzy soft set theory and its applications, Turk. J. Fuzzy Syst. 2010; 1(1), 21-35.

[6] Çağman, N.; Karataş, S.; Enginoglu, S. Soft topology, Comput. Math. Appl. 2011; 62, 351-258.

[7] Çağman, N.; Enginoğlu, S. Soft matrix theory and its decision making, Comput. Math. Appl. 2010; 59, 33083314 .

[8] Gierz, G.; Hofmann, K.H.; Keimel, K.; Lawson, J.D.; Mislove, M.; Scott, D.S. Continuous Lattices and Domains, Encyclopedia of Mathematics and its Applications 93.

[9] Guan, X.; Li, Y.; Feng, F. A new order relation on fuzzy soft sets and its applications, Soft Compt. 2013; 17, 63-70.

[10] Hrbacek, K.; Jech, T. Introduction to Set Theory, Marcel Dekker Inc., 1984.

[11] Husain, S.; Ahmad, B. Some properties of Soft Topological Spaces, Comput. Math. Appl. 2012; 62, 40584067.

[12] Jun, Y.B.; Park, C.H. Applications of Soft Sets in Ideal Theory of BCK/BCI Algebras, Inform. Sciences, 2008; 178, 2466-2475.

[13] Jun, Y.B.; Park, C.H. Applications of Soft Sets in Hilbert Algebras, Iran J. Fuzzy Syst. 2009; 6(2), 75-88.

[14] Jun, Y.B.; Kim, H.S.; Neggers, J. Pseudo d-algebras, Inform. Sciences, 2009; 179, 1751-1759.

[15] Jun, Y.B.; Lee, K.J.; Khan, A. Soft Ordered Semigroups, Math. Log. Quart. 2010; 56(1), 42-50.

[16] Maji, P.K.; Biswas, R.; Roy, A.R., Fuzzy Soft sets, Journal Fuzzy Mathematics, 2001; 3, 589-602.

[17] Maji, P.K.; Biswas, R.; Roy, A.R. Soft set theory, Comput. Math. Appl. 2003; 45, 555-562.

[18] Min, K.W. A Note on Soft Topological Spaces, Comput. Math. Appl. 2011; 62, 3524-3528.

[19] Molodtsov, D. Soft Set Theory-First Results, Comput. Math. Appl. 1999; 37, 19-31.

[20] Nazmul, S.K.; Samanta, S.K. Neighbourhood properties of soft topological spaces, Ann. Fuzzy Math. Inform., 2013; 6, 1- 15.

[21] Onyeozili, I.A.; Gwary, T.M. A study the Fundamentals of Soft Set Theory, International of Sciences and Technology Research, 2014; 3(4) 132-143.

[22] Park, J.H.; Kim, O.H.; Kwun, Y.C. Some properties of equivalence soft set relations, Comput. Math. Appl. 2012; 63, 1079-1088.

[23] Roy, S.; Samanta, T.K. An Introduction of a Soft Topological Spaces Proceeding of UGC sponsored National seminar on Recent trends in Fuzzy set theory, Rough set theory and Soft set theory at Uluberia College on 23rd and 24th September, 2011 ISBN 978-81-922305-59, 9-12, 2011.

[24] Sayed, A.F. Continuity of partially ordered soft sets via soft Scott topology and soft sobrification, Bulletin of Mathematical Sciences and Applications, 2014; 3(3), 98113.

[25] Seselja, B.; Tepavcecic A., A note on a natural equivalence relation on fuzzy power set, Fuzzy Sets and Systems, 2004; 148, 201-210.

[26] Sut, D.K. An Application of Fuzzy Soft Relation in Decision Making Problems, International Journal of Mathematics Trends and Technology 2012; 3(2).

[27] Shabir, M.; Naz, M. On Soft Topological Spaces, Comput. Math. Appl. 2011; 61, 1786-1799.

[28] Tanay, B.; Yaylal1, G. New structures On Partially Ordered Soft Sets and Soft Scott Topology, Ann. Fuzzy Math. Inform., 2014; 7, 89-97.

[29] Varol, B.P.; Aygün, H. On soft Hausdorff spaces, Ann. Fuzzy Math. Inform., 2013; 5, 15-24.

[30] Yang, H.; Guo, Z. Kernels and Closures of Soft Set Relations, and Soft Set Relation Mappings, Comput. Math. Appl. 2011; 61, 651-662.

[31] Zhang, X. On Interval Soft Sets with Applications, International Journal of Computational Intelligence Systems, 2014; 7(1), 186-196.

[32] Zorlutuna, İ.; Akdağ, M.; Min, W.K.; Atmaca, S. Remarks on Soft Topological Spaces, Ann. Fuzzy Math. Inform., 2012; 3, 171-185. 